\title{
ANÁLISE DE RECEITUÁRIOS ANTIMICROBIANOS DISPENSADOS EM UMA \\ FARMÁCIA COMERCIAL NO MUNÍCIPIO DE JUAZEIRO DO NORTE - CE
}

\author{
ANALYSIS OF ANTIMICROBIAN REVENUE DISPENSED IN A COMMERCIAL \\ PHARMACY IN JUAZEIRO NORTH - CE
}

\author{
Vanessa Vieira Sampaio', Annalu Moreira Aguiar², Alice Rodrigues de Oliveira \\ Araruna $^{3}$
}

\begin{abstract}
1 - Acadêmica do Curso de Bacharelado em Farmácia na Faculdade de Medicina de Juazeiro do Norte Estácio FMJ. E-mail: vanessa17740@gmail.com

2 - Profa . Esp. Docente em Farmácia na Faculdade de Medicina de Juazeiro do Norte - Estácio FMJ.

3 - Farmacêutica, Docente no curso de Farmácia - Faculdade de Medicina do Juazeiro- FMJ Estácio.

Autor par correspondência; vanessa17740@hotmail.com
\end{abstract}

\section{RESUMO:}

Visando a redução da comercialização e uso inadequado de medicamentos antibióticos, a Agência Nacional de Vigilância Sanitária (ANVISA) publicou a RDC 44/10, sendo posteriormente regida para RDC 20/11 que determina parâmetros de prescrição e dispensação desses medicamentos. Nesse sentido o presente artigo tem como objetivo, analisar a legibilidade das prescrições de antimicrobianos dispensados em uma farmácia comercial na cidade de Juazeiro do Norte - CE. O estudo caracterizou-se como sendo observacional e retrospectivo, seguindo orientações quantitativas e qualitativas, foram avaliadas prescrições médicas de antimicrobianos dispensadas em uma farmácia comercial na cidade de Juazeiro do Norte - CE. A amostra foi composta por 185 receitas de antimicrobianos que foram dispensados no período de 1 a 31 de outubro de 2019. Das receitas avaliadas, 76,64 \% apresentaram duas vias, sem rasuras e com o prazo de validade de dez dias. Das prescrições, $91,12 \%$ não apresentaram o endereço dos pacientes, $57,10 \%$ das receitas apresentavam boa legibilidade para serem dispensadas, $71,56 \%$ dos receituários prescritos eram de forma manuscrita. As prescrições estavam de acordo com os preceitos de legalidade vigente no âmbito de farmácia comercial, embasado pela ANVISA e RDC $n^{\circ} 20 / 2011$, sob respaldo e supervisão de seu cumprimento pelo farmacêutico do estabelecimento, visando promover uma dispensação segura, eficaz e que contribua na informação e melhoria do padrão de vida dos pacientes.

Palavras Chave: Antimicrobianos, prescrições, medicamentos.

\section{ABSTRACT:}

In order to reduce the commercialization and inappropriate use of antibiotic drugs, the National Health Surveillance Agency (ANVISA) published RDC 44/10, which is later governed by RDC 20/11, which determines prescribing and dispensing parameters for these drugs. In this sense, this article aim to analyze the legibility of antimicrobial prescriptions dispensed in a commercial pharmacy in the city of Juazeiro do Norte - CE. The study was characterized as observational and retrospective, following quantitative and qualitative guidelines, were evaluated medical prescriptions of antimicrobials dispensed in a commercial pharmacy in the city of Juazeiro do Norte - CE. The sample consisted of 185 antimicrobial recipes that were dispensed from October 1 to 31, 2019. Of the recipes evaluated, $76.64 \%$ had two copies, without erasures and with a shelf life of ten days. Of the 
prescriptions, $91.12 \%$ did not have the address of the patients, $57.10 \%$ of the prescriptions had good readability to be dispensed, $71.56 \%$ of the prescribed prescriptions were handwritten. The prescriptions were in accordance with the legality precepts in force in the scope of commercial pharmacy, based on ANVISA and RDC No. 202011, under the support and supervision of its compliance by the pharmacist of the establishment, aiming to promote a safe, effective dispensation that contributes to information and improvement of patients' standard of living.

Keywords: Antimicrobials, prescriptions, medications.

\section{INTRODUÇÃO}

À medida que surgem novas patologias acometendo a sociedade, há necessidade de a ciência desenvolver novas alternativas que tragam êxito em tratamentos que promovessem a cura humana. Em maio de 1940, em estudos, dois pesquisadores, Chain Florey e Abraham isolaram um extrato de penicilina, o qual foi testado em modelos animais, demonstrando eficácia, conferindo-Ihes o prêmio Nobel de Medicina pela descoberta (RANG et al., 2011).

Os antimicrobianos retratam uma das mais importantes destas descobertas. A partir de 1942, eles começaram a ser utilizados na prática médica, sendo a penicilina $G$, uma referência histórica na terapêutica clínica (AMATO; NICODEMO; LOPES, 2007). Os antibióticos tornaram-se medicamentos efetivos na destruição de microrganismos ou na limitação da sua proliferação (ANVISA, 1998).

Para o tratamento de infecções causadas por microrganismos, comumente recorrese ao tratamento de antimicrobianos. Contudo, o uso irracional desses medicamentos, como a interrupção do tratamento antes do prazo em período inferior a eliminação da bactéria ou mesmo sem indicação médica, podem gerar uma série de problemas para a saúde da população em geral (MAIER; ABEGG, 2007).

Conforme Wannmacher (2006), as orientações e indicações de tratamentos com antimicrobianos devem seguir critérios bem definidos para diminuir a difusão de resistência bacteriana.

A sociedade moderna tem acentuado a preocupação pela busca da qualidade de vida, a fim de obter meios de prevenção e tratamento de eventuais problemas de saúde mais comuns em seu meio (FERNANDES et al., 2015). Fatores como a automedicação e mesmo o não segmento de um tratamento correto conforme a prescrição e orientação médica podem interferir na eficácia da utilização dos medicamentos adotados, sobretudo porque cada avaliação e diagnóstico podem apresentar a curto médio prazo (VIEIRA; VIEIRA, 2019). 
$\mathrm{Na}$ medida em que os antibióticos são usados inadequadamente, os microrganismos vão desenvolvendo resistência (BRAOIOS, et al., 2013). O uso inadequado dessa classe é responsável por mais de $10 \%$ das internações hospitalares em todo 0 mundo. Anualmente, de acordo com a Organização Mundial de Saúde (OMS), mais de 50 $\%$ de todos os medicamentos são incorretamente prescritos, dispensados e vendidos, e mais de $50 \%$ dos pacientes fazem o uso incorreto (OMS, 2010).

Visando garantir o uso correto dos antimicrobianos, a assistência farmacêutica é essencial para garantir o uso seguro e racional destes medicamentos. A assistência farmacêutica é um modelo de prática farmacêutica, concebendo práticas, conceitos éticos, comportamentos, desenvolturas e compromisso na prevenção de doenças, promoção e recuperação a saúde (CASTRO et al., 2006). A assistência farmacêutica inclui ocupações inter-setoriais voltadas com intuito individual ou coletivo de uma comunidade, em que se tem o medicamento como insumo principal de acesso garantido para o uso racional (VIEIRA, 2010).

Com finalidade de reduzir o uso inadequado de medicamentos e conter a comercialização dos antibióticos a Agência Nacional de Vigilância Sanitária publicou a RDC 44/10 (BRASIL, 2011), posteriormente regida para RDC 20/11 que determina parâmetros de prescrição e dispensação desses medicamentos (FERREIRA; FERREIRA, 2015). Nesse sentido o presente artigo tem como objetivo, analisar a legibilidade das prescrições de antimicrobianos dispensados em uma farmácia comercial na cidade de Juazeiro do Norte - CE.

\section{MATERIAL E MÉTODOS}

O presente estudo caracterizou-se como sendo observacional e retrospectivo, seguindo orientações quantitativas e qualitativas, onde foram avaliadas prescrições médicas de antimicrobianos dispensadas em uma farmácia comercial na cidade de Juazeiro do Norte - CE. A amostra foi composta por 185 receitas de antimicrobianos que foram dispensados no período de 1 a 30 de outubro de 2019, não houve contato algum com os pacientes dos receituários apenas com dados internos. Os critérios de inclusão e exclusão da amostra ocorreram a partir das receitas retidas na farmácia no período supracitado, assim como somente foram analisados receituários de prescrições de antimicrobianos.

A pesquisa foi realizada mediante aprovação do comitê de ética em pesquisa da Faculdade de Medicina Estácio de Juazeiro do Norte - CE, sob o protocolo: 
22422819.0.0000.8074 e parecer da aprovação de $n^{\circ}$ 3.706.796, o responsável técnico do estabelecimento assinou o termo de consentimento autorizando a pesquisa no estabelecimento comercial.

Para coleta dos dados, utilizou-se de um questionário semiestruturado, elaborado pela pesquisadora e a orientadora, contendo variáveis que respondessem aos objetivos traçados no estudo.

A coleta ocorreu em duas etapas. Na primeira, foi coletado e analisado cada receituário no período de outubro de 2019 , respondendo as perguntas como se a receita apresentava as 2 vias, se o preenchimento estava correto, sem rasuras e dentro do prazo de validade, constância do nome do medicamento, concentração, forma farmacêutica e posologia, receituário estava legível ou ilegível e prescrição digitada ou escrita a mão.

A segunda etapa ocorreu a partir da interpretação e discussão da coleta, onde cada variável da pesquisa foi respondida através da análise individual de cada receita, distribuídas numa planilha do banco de dados do Microsoft Office Excel 2019 e posteriormente apresentadas em gráficos ilustrados.

A análise dos resultados foi desenvolvida através da quantificação dos dados mais relevantes e posteriormente qualificação dos dados que apresentaram maior percentual na coleta, assim como esse foram discutidos e complementados a partir de estudos semelhantes e autores presentes na literatura atual, assim como por meio do embasamento da RDC20/11.

\section{RESULTADOS E DISCUSSÕES}

Os resultados foram obtidos através de análise junto a 185 receituários de prescrições de antimicrobianos coletadas numa farmácia comercial no intuito de obter os objetivos inicialmente propostos. A seguir serão apresentados os gráficos ilustrando os resultados do estudo com suas devidas discussões acerca do tema investigado.

Conforme o gráfico 1, houve predominância de 76,64 \% das prescrições que se apresentaram em duas vias, sem rasuras e como prazo de validade de dez dias. Os resultados do gráfico corroboram com os achados de Martins et al., (2014) o qual em seu estudo obteve $87,7 \%$ das prescrições tinham data de emissão.

Apesar do elevado percentual de receitas corretas, é oportuno destacar também que das $23,36 \%$ que apresentaram alguma informação incompleta se deteve ao fato de que algumas receitas chegaram até o estabelecimento somente em uma via, em situações 
como essa, havendo a necessidade do atendente de farmácia juntamente com orientação do farmacêutico emitir uma cópia da mesma catalogando lote, validade e o Registro do Ministério da Saúde (MS) do medicamento.

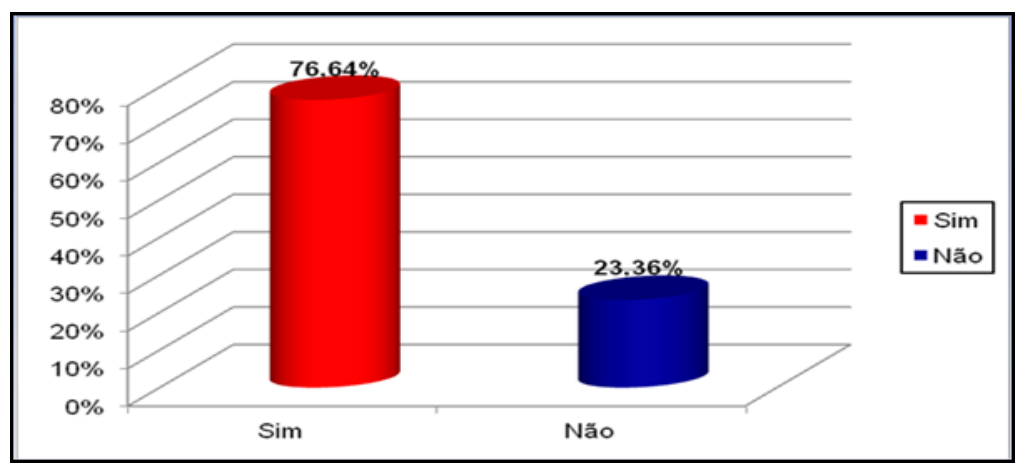

Fonte: Da pesquisa (2019)

\section{Gráfico 1: Receitas que apresentam duas vias com preenchimento correto, sem} rasuras e dentro do prazo de validade.

A data de emissão do receituário é fundamental, pois segundo a RDC nํำ 20/2011, o aviamento da receita de antimicrobiano deve estar dentro do prazo de dez dias (BRASIL, 2011).

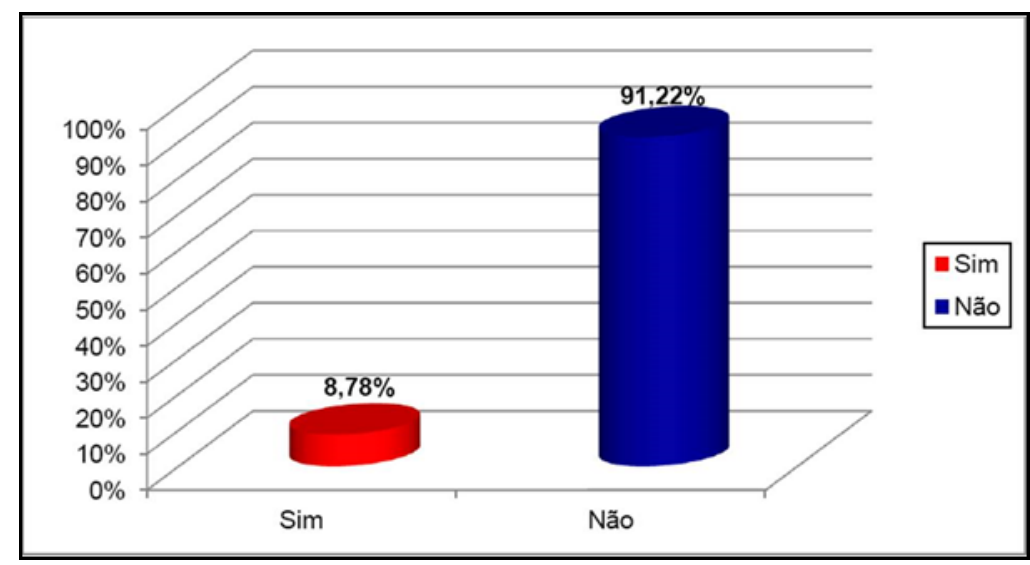

Fonte: Da pesquisa (2019)

Gráfico 2: Preenchimento do endereço do paciente na receita médica.

O gráfico 2 expõe que grande maioria das prescrições não apresentaram o endereço do paciente em sua estrutura, sendo em dados estatísticos 91,22\% delas inexistiam essa informação. 
Os dados corroboraram com o estudo de Oliveira; Destefani (2011) que obtiveram $58 \%$ das receitas sem o endereço completo. Concordando também com Silva; Bandeira; Oliveira (2012) os quais, das 1005 prescrições avaliadas, 100 \% inexistia endereço do paciente, apesar de ser obrigatório segundo a legislação.

Dados diferentes foram apresentados no estudo de Mastroianni et al., (2009), de modo que $100 \%$ dos receituários continham o nome completo, conferindo legibilidade das receitas. A prescrição é um documento legal e um meio de comunicação dos profissionais da saúde, devendo este conter informações completas do paciente visando ampliar o acompanhamento aos pacientes (MASTROIANNI et al., 2009).

O preenchimento do endereço do paciente torna a prescrição mais fidedigna, uma vez que amplia o atendimento do médico com o paciente e deste com a farmácia que irá realizar a dispensação do medicamento de forma a possibilitar uma eventual informação, orientação, correção no tratamento ou até mesmo um contato secundário em caso de dúvidas ou eventuais erros de dispensação.

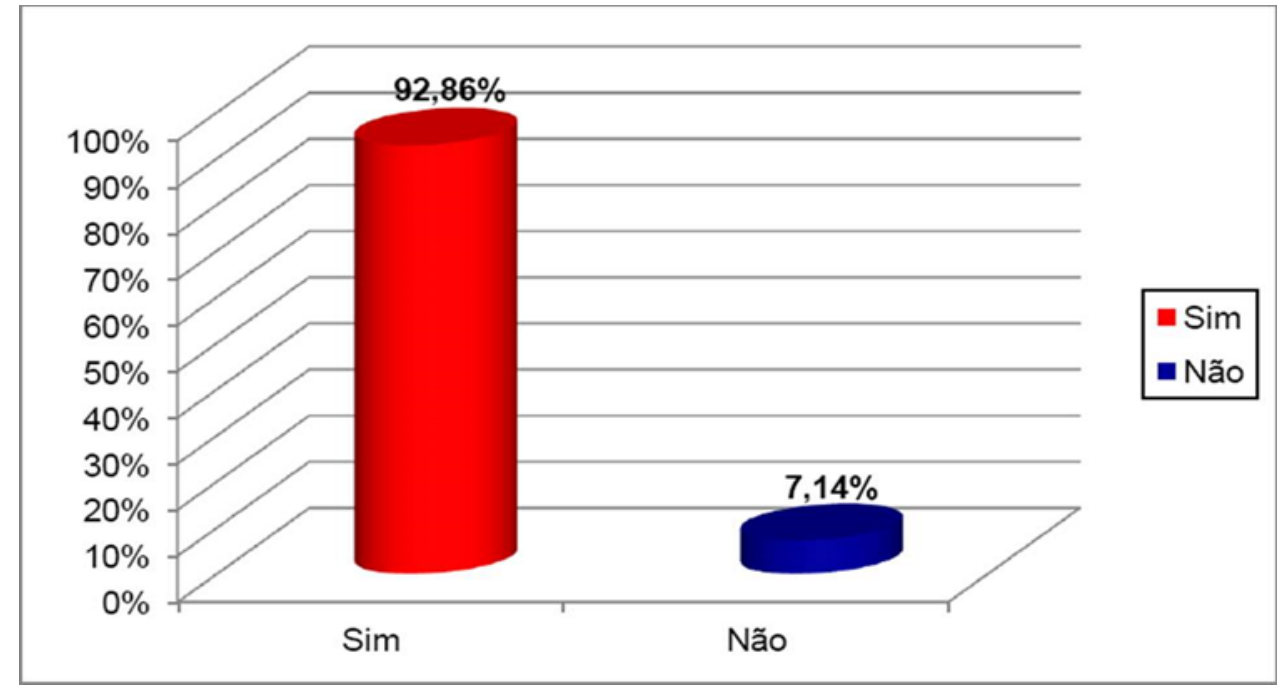

Fonte: Da pesquisa (2019)

Gráfico 3: Receitas com nome do medicamento ou substância (DCB), concentração, forma farmacêutica, quantidade e posologia.

Ainda relacionado à estrutura do receituário de antimicrobianos, o gráfico 3 mostra que 92,86 \% delas apresentavam nome comercial ou da substância, concentração, forma farmacêutica e posologia e 7,14 \% apresentou esses dados incompletos.

Os números apresentados concordam com os achados de Silverio; Leite (2010), que obtiveram em $90 \%$ dos receituários analisados a presença da forma farmacêutica 
completa. Já em Aldrigue et al., (2006), em uma análise de prescrições dispensadas em farmácia comunitária, a posologia foi completa em apenas $47 \%$ dos casos.

Os números vão de encontro ao que rege a Portaria GM/MS 3.916/98 e a Portaria SVS/MS 344/98, que tem a prescrição como um ato de definir o medicamento a ser consumida pelo paciente com a respectiva dosagem, duração do tratamento e orientação de uso (MASTROIANNI et al., 2009).

Muitos pacientes podem já ter realizado tratamento com antibióticos ou mesmo ser alérgico a algum princípio ativo, de modo que a presença deste princípio ativo ou conhecimento do que ele irá consumir pode evitar possíveis reações alérgicas, uma vez que quase sempre é somente no ambiente da farmácia comercial através da orientação do farmacêutico que há contato com o medicamento e orientações sobre possíveis reações e uso eficaz do produto.

Entre as 7,14 \% das receitas que não estavam de acordo com as variáveis investigada no gráfico 3, o que mais se destacaram foram os relacionados a posologia, uma vez que as prescrições que traziam a quantidade de caixas de um dado medicamento poderia ser insuficiente ou mesmo ultrapassar o tempo necessário ao tratamento, nesses casos notou-se que a dispensação seguiu a posologia e tempo de tratamento independentemente da quantidade de caixas descritas.

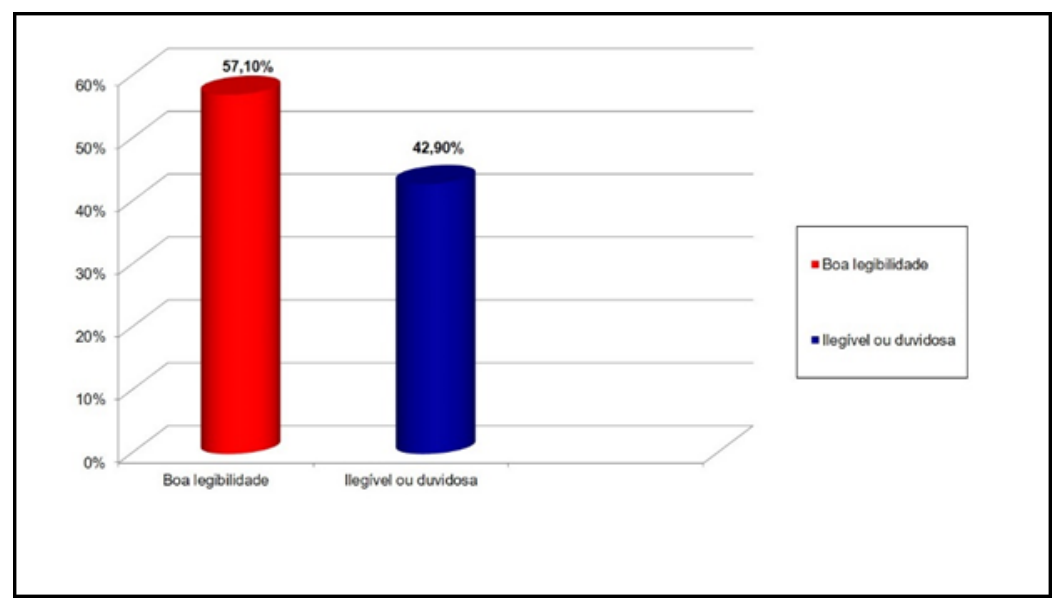

Fonte: Da pesquisa (2019)

\section{Gráfico 4: Legibilidade das prescrições nos receituários.}

O Gráfico 4 ilustra que em relação à transcrição da estrutura do receituário, prevaleceu em 57,10 \% garantia de legibilidade na identificação da mesma. A garantia da legibilidade de prescrições médicas pode facilitar a dispensação na farmácia, como também 
pode gerar maior segurança ao paciente na utilização, uma vez que há a possibilidade de discriminar todos os medicamentos e a formas de administração, sem comprometimento do tratamento.

Em um estudo desenvolvido em uma farmácia privada no município de Quedas no Paraná, Pegoraro (2017) também obteve maioria de prescrições com legibilidade adequada, sendo elas representadas por $90 \%$ de sua amostra.

Apesar do destaque apresentado nas receitas que apresentaram legibilidade, notase a ilustração que em 42,90 \% das prescrições apresentaram-se ilegíveis ou duvidosas, podendo estar diretamente associados às prescrições transcritas a mão.

$\mathrm{Na}$ pesquisa de Júnior (2015) 35,1 \% das receitas analisadas apresentaram prescrição de forma ilegível, em algumas delas a dispensação se mostrou impossível, em alguns momentos se fez necessária à comunicação com o profissional prescritor, e em outras devido à experiência do farmacêutico foi possível realizar a dispensação corretamente.

Os dados estruturais das prescrições são essenciais e devem estar devidamente corretos, de forma legível e quando a prescrição for manuscrita precisam ser revisadas criteriosamente, pois os erros podem ocorrer facilmente, seja na dispensação ou na terapêutica inadequada realizada pelo paciente (SANAJOTTO; PILOTO, 2014).

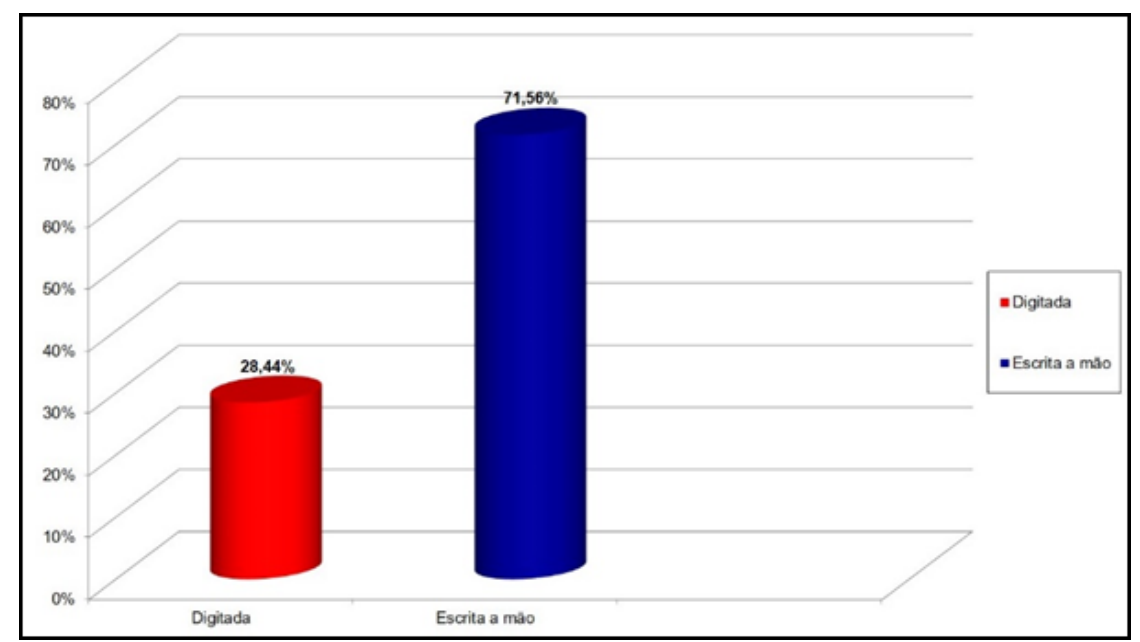

Fonte: Da pesquisa (2019)

\section{Gráfico 5: Característica da prescrição quanto à transcrição no receituário.}

Os resultados obtidos no gráfico 5 ratificam as informações encontradas no gráfico 4, sendo que aqui houve prevalência de $71,56 \%$ de receituários prescritos pelos médicos 
de forma manuscrita.

Os dados do gráfico corroboraram com os resultados do estudo de Lima; Abreu (2017), uma vez que nas prescrições que eles coletaram 63,84 \% delas eram manuscritas e $36,16 \%$ digitadas.

O percentual apresentado concorda ainda com os números de Martins et al., (2014) que em uma farmácia comercial de Imperatriz no Maranhão foi encontrado que 9,2 \% das prescrições analisadas, estas apresentavam-se na forma digitadas e 90,8 \% na forma manuscritas.

Existe grande parte de prescritores que emitem as receitas na forma impressa, em contrapartida ainda há prescritores que recorrem aos métodos tradicionais, em que a prescrição tende a ser realizada de forma manuscrita contribuindo por tornar ilegível, e essa ilegibilidade pode ser um dos principais fatores de indução a erros no momento da dispensação (SILVÉRIO; LEITE, 2010).

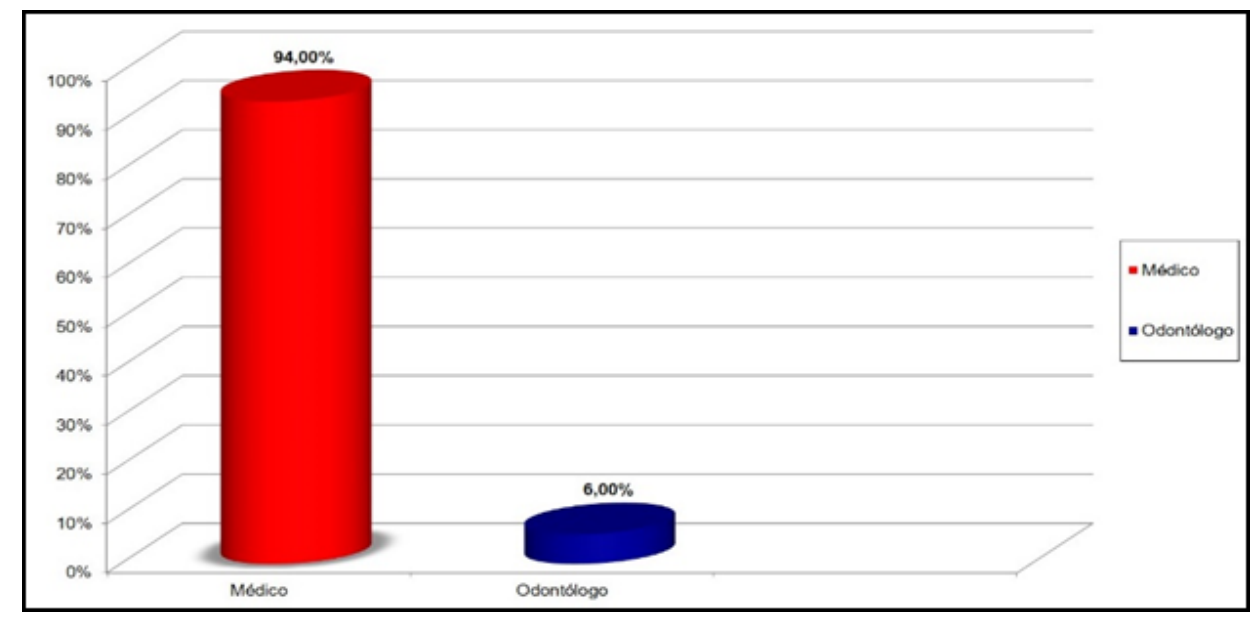

Fonte: Da pesquisa (2019).

\section{Gráfico 6: Principal profissional prescritor das receitas.}

Em relação ao profissional de saúde prescritor das receitas em análise, o gráfico 6 traz uma maioria, 94\% realizada por profissionais de medicina em suas diferentes especialidades. Os dados percentuais corroboram com a pesquisa de Nicolino et al., (2008), com predominância de prescrições realizadas por médicos 95,5 \% e 4,5 \% de prescrições realizadas por odontólogos. Os números também se assemelham ao estudo de Júnior (2015) que obteve 96 \% das prescrições emitidas por Médicos. 


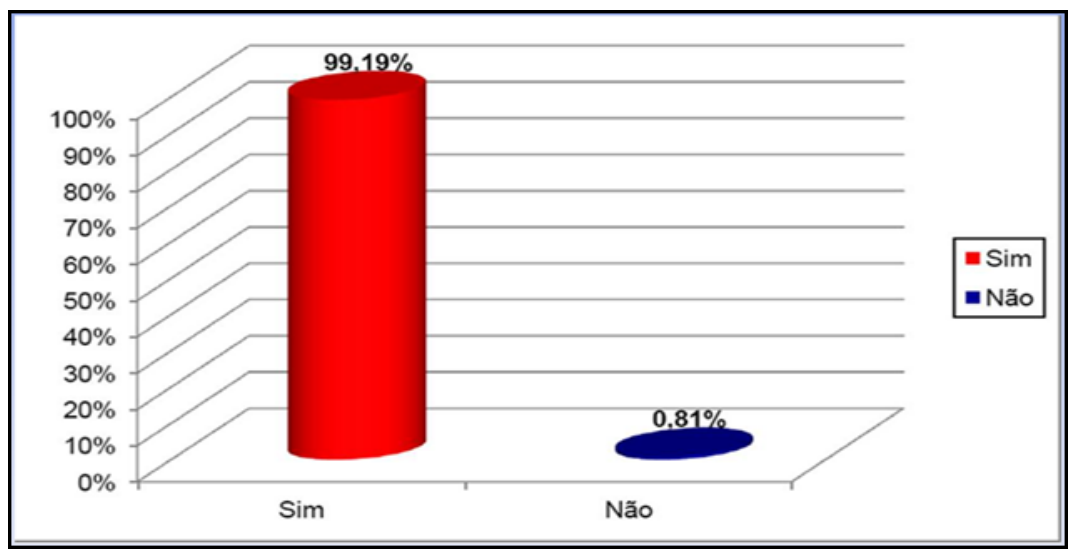

Fonte: Da pesquisa (2019).

\section{Gráfico 7: Apresentação do carimbo na prescrição das receitas.}

O gráfico 7 expõe a predominância de $99,19 \%$ das receitas coletadas encontravam-se precedidas do carimbo com as informações referentes ao prescritor, tais como: Nome completo, especialidade e número de registro no Conselho Regional de Medicina (CRM).

Os resultados corroboram com os achados de Júnior (2015), que obteve 80 \% das receitas devidamente carimbadas diante de $20 \%$ sem carimbo. Os dados também se assemelham aos achados de Nascimento; Magalhães (2013) tendo eles obtido 99,21\% das receitas devidamente assinadas e/ou carimbas pelo profissional prescritor.

O carimbo do prescritor é um dos componentes essenciais para aceitação da receita no estabelecimento comercial, de modo que a ausência deste pode sim implicar em não obtenção do medicamento no local. Uma particularidade para aceitação de prescrições com ausência de carimbo se aplica as receitas que possam vir padronizadas com a logomarca do estabelecimento e timbre, juntamente com dados do prescritor, tais como $\mathrm{CRM} / \mathrm{CRO}$, nome completo, especialidade e que estejam devidamente assinadas.

Essa orientação fica ainda mais ainda mais nítida através da RDC 20/2011, que preconiza que a receita de antimicrobianos deverá trazer em sua composição, nome do profissional com sua inscrição no Conselho Regional ou nome da instituição, endereço completo, telefone, assinatura e carimbo, podendo ser comprovada por marcação gráfica e data da emissão (BRASIL, 2011). 


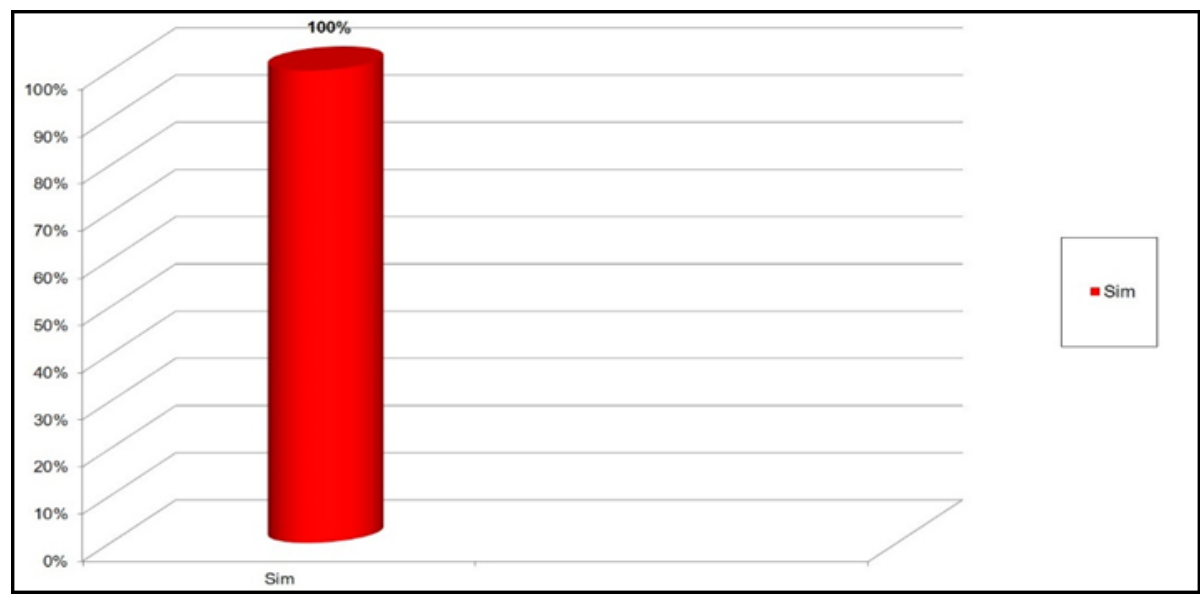

Fonte: Da pesquisa (2019).

\section{Gráfico 8: Apresentação da assinatura na prescrição das receitas.}

De acordo com os percentuais apresentados no gráfico 8 , percebe-se que de modo unânime que $100 \%$ das prescrições retidas na farmácia comercial, apresentavam assinatura do prescritor, questão que pode estar atrelada ao fato de que o estabelecimento cumpre as normas regulamentadas pela ANVISA em relação a aviamento de receitas somente sob avaliação e autorização dos farmacêuticos.

A assinatura do profissional de saúde ratifica e assegura a confiabilidade documental atribuída à receita, independentemente do tipo de medicamento. Questão essa que concorda com Mastroianni et al., (2009), que os dados essenciais que estejam ausentes, como o nome do paciente, assinatura, carimbo do prescritor e data de emissão são capazes de acarretar fraudes e falsificação de prescrições ou notificações.

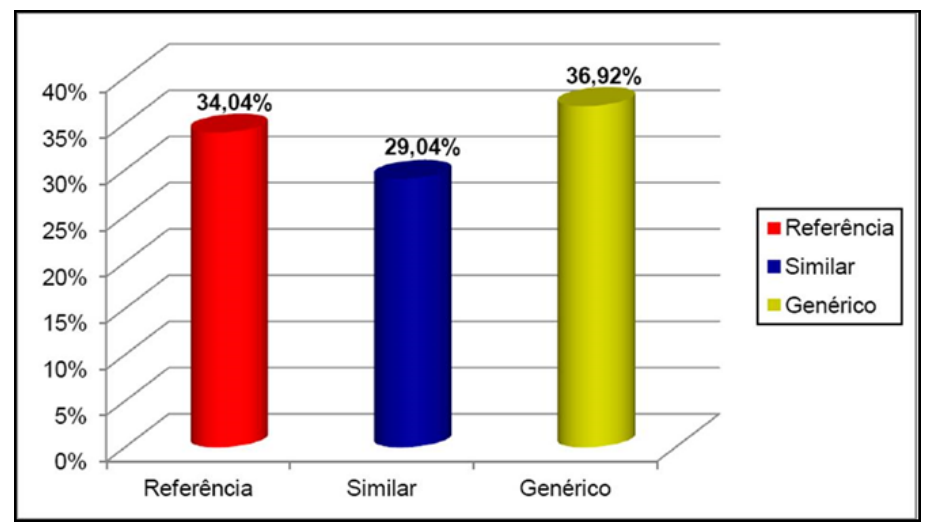

Fonte: Da pesquisa (2019).

Gráfico 9: Classes comerciais de antibióticos prescritos. 
Houve predominância de prescrições relacionadas a medicamentos genéricos (Gráfico 9) em 36,92 \%, seguido de 34,04 \% de medicamentos de referência e 29,04 \% de medicamentos similares. Apesar da pouca margem percentual de diferença entre eles, houve maior indicação do princípio ativo nas prescrições médicas.

Os resultados corroboraram com os achados de Lima; Abreu (2017) com 53,15\% das prescrições com denominação genérica, e por Martins et al., (2014) com denominação genérica 53,4 \% das receitas. Júnior (2015) encontrou dados, com $52 \%$ das prescrições com medicamentos de referência, e 48 \% com nome da substância e princípio ativo. Santos; Nitrini (2004) encontram resultado de 30,6 \% de prescrições pelo nome genérico, as quais eram emitidas pelo SUS, destacando no mesmo, que as prescrições devem sempre trazer o nome DCB ou DCl.

Tanto a literatura quanto os órgãos de saúde trazem em seus documentos que não há diferenças na ação dos medicamentos genéricos e os de referência em relação a sua ação terapêutica orgânica, assim como, eles detêm ampla aceitação social em consideração ao baixo custo e a qualidade comprovada por testes de equivalência e biodisponibilidade.

Os dados podem estar associados ao fato de grande parte das receitas terem sida prescritas em órgãos públicos de saúde, os quais em sua maioria somente dispõe dos genéricos, assim como amplia a possibilidade e da liberdade do paciente escolher até mesmo por aquele que dispõe de um preço mais acessível.

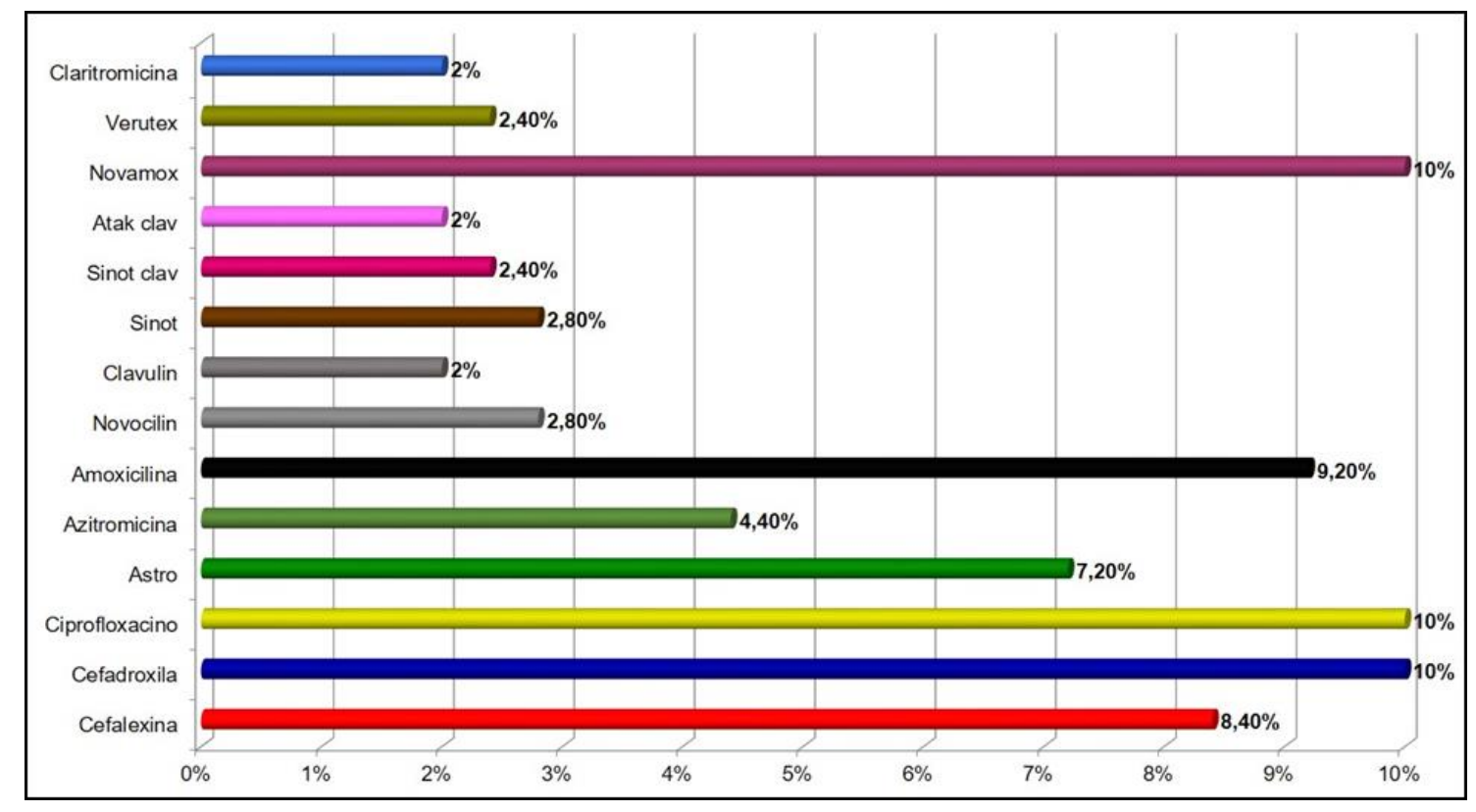

Fonte: Da pesquisa (2019).

Gráfico 10: Medicamentos mais prescritos. 
O gráfico 10 em relação aos demais apresentados anteriormente, traz uma particularidade, por se tratar de uma das variáveis de resposta transcrita deteve ampla quantidade de descrições nominais de marcas comerciais de referência, similares e genéricos. Contudo, em especial quatro tiveram maior destaque percentuais, $10 \%$ Novamox, $10 \%$ Ciprofloxacino, $10 \%$ Cefadroxila e 9,20 \% Amoxicilina.

Somado aos dados de maior destaque, percebe-se que em relação ao princípio ativo dos nomes apresentados em sua totalidade houve predominância dos antibióticos compostos por Amoxicilina, pois Sinot, Clavulin e Novocilin se constituem no mesmo princípio ativo, assim como ele associado Amoxicilina + Clavulonato nos nomes comerciais Novamox, Atak Clav e Sinot Clav.

Os dados em questão corroboram como Lima; Abreu (2017), que coletaram um percentual de 23,58 \% de Amoxicilina, 16,35 \% Cefalexina, 11,32 \% Azitromicina e 6,28 \% Amoxicilina + clavulonato.

Os números obtidos convergem ainda com os encontrados no estudo de Pescador; Spada (2015), apresentando 21,12 \% das prescrições relacionadas à classe da Penicilina em suas diversas dosagens e combinações. Assim como em Ferreira et al., (2014), o qual coletou 55 receitas com prescrições de Amoxicilina + Clavulonato, 47 Azitromicima e 40 Amoxicilina.

O estudo de Oliveira (2004) situa a Amoxicilina como o antibiótico mais indicado nas prescrições médicas, provavelmente pela sua ampla ação bactericida, evidenciando ser frequentemente utilizado em infecções de âmbito respiratório.

\section{CONSIDERAÇÕES FINAIS}

A legibilidade das prescrições foi obtida como um ponto importante a fim de evitar eventuais erros de leitura e interpretação do nome comercial ou substância, dosagem, forma farmacêutica e posologia, contudo o que pode ser legível para o farmacêutico e atendente pode ser inacessível ao paciente, uma vez que a maioria das receitas ainda é manuscritas, ampliando a necessidade de comunicação e informação junto ao profissional na farmácia a fim de sanar as eventuais dúvidas.

Nesse sentido, as discussões estabelecidas e resultados coletados e debatidos comprovam que a legibilidade na receita está intimamente ligada a seus componentes, observando que as informações referentes aos pacientes foram devidamente encontradas, contudo havendo ainda a necessidade de uma complementação dos dados referentes ao 
endereço dos pacientes nas prescrições para uma plenitude das informações.

A partir das questões obtidas na pesquisa, percebeu-se que não houve erros relevantes de prescrições, uma vez que o estabelecimento se assegura de seguir todos os preceitos farmacêuticos que se enquadram nos padrões estabelecidos pelos órgãos que regulamentam o uso e dispensação de medicamentos de acordo com a RDC n 202011.

As prescrições atendem aos preceitos de legalidade vigente no âmbito de farmácia comercial, embasado pela ANVISA e RDC $n^{\circ} 20 / 2011$, sob respaldo e supervisão de seu cumprimento pelo farmacêutico do estabelecimento, visando promover uma dispensação segura, eficaz e que contribua na informação e melhoria do padrão de vida dos pacientes.

\section{REFERÊNCIAS}

ALDRIGUE, R. F. T.; CORRER C. J.; MELCHIORS, A. C.; PONTAROLO, R. Análise da Completude de Prescrições Médicas Dispensadas em uma Farmácia Comunitária de Fazenda Grande - Paraná (Brasil). Acta Farm. Bonaraense 25. 454 - 459. 2006.

AMATO, N. V.; NICODEMO, A.C.; LOPES, H. V. Antibióticos na prática médica. Rev. Inst Med trop S Jan./Feb. 2007.

ANVISA - Agência Nacional de Vigilância Sanitária. DOU № 87, segunda-feira, 9 de maio de 2011. Seção 1, páginas 39 a 41 RESOLUÇÃO-RDC № 20, DE 5 DE MAIO de 2011.

BRAOIOS, A. et al. Uso de Antimicrobianos pela população da cidade de Jataí-GO, Brasil. Revista Ciência e Saúde Coletiva, Rio de Janeiro, v. 18, n. 10, p. 3056, 2013.

BRASIL. Ministério da Saúde. Agência Nacional de Vigilância Sanitária. Resolução da Diretoria Colegiada - RDC no 20, de 5 de maio de 2011. Dispõe sobre o controle de medicamentos à base de substâncias classificadas como antimicrobianos, de uso sob prescrição, isoladas ou em associação. Diário Oficial da União, Brasília, 9 de maio de 2011.

CASTRO, M. S.; CHEMELLO, C.; PILGER, D.; JUNGES, F.; BOHNEN, L.; ZIMMERMAN, L. M.; et al. Contribuição da atenção farmacêutica no tratamento de pacientes hipertensos. Rev Bras Hipertens. 13(3):198-202, 2006; 
COSTA, G. D. et al. Avaliação da atenção à saúde da criança no contexto da Saúde da Família no município de Teixeiras, Minas Gerais (MG, Brasil). Ciência \& Saúde Coletiva, Rio de Janeiro, v. 16, n. 7, p. 3229-3240, jul. 2011.

DEL FIOL, F. de S.; LOPES, LUCIANE C.; TOLEDO, M. I. de; FILHO, S. B. Perfil de prescrições e uso de antibióticos em infecções comunitárias. Revista da Sociedade Brasileira de Medicina Tropical, Uberaba, v. 43, n. 1, fev, 2010.

FERNANDES, C. S. et al. A Importância das Famílias nos Cuidados de Enfermagem: Atitudes dos Enfermeiros em Meio hospitalar. Rev. Enfermagem. Ref., Coimbra, v. serIV, n. 7, p. 21-30, dez. 2015.

FERREIRA, F. C. S.; LUCENA, T. N.; FREITAS, R. M. et. al., Análise do perfil das prescrições de antibióticos em uma farmácia comunitária no município de Quixadá-Ceará. Revista Expressão Católica, v. 3, n. 2, p. 183-188, 2014.

FERREIRA, T. A.; FERREIRA, F. D. Qualidade da prescrição de antimicrobianos comercializados na Região Noroeste do Paraná, Brasil. Revista de Saúde e Biologia, v. 10, n. 1, p. 131-137, 2015.

JÚNIOR, A. G. Análise das prescrições de antimicrobianos dispensados em uma drogaria da cidade de Colider-MT. FACIDER Revista Científica, Colider. 2015; (08), 2015.

LIMA, M. C. S, ABREU, B. S. RDC 20/2011: Análise de prescrições médica de antimicrobianos em uma drogaria do distrito federal. Rev. Cient. Sena Aires. 2017; 6(2): 103-8.

MAIER, C. R.; ABEGG, M. A. Avaliação da utilização de antibióticos por profissionais de saúde e pela população na cidade de Toledo, Paraná, Brasil. Arquivos de Ciências da Saúde da Unipar, 11(1): 19-26, 2007.

MARTINS, N. B. et al. Análise de prescrição médica de antibióticos de uma farmácia comercial do município de Imperatriz-MA. Revista Científica do ITPAC. Araguaína, v.7, n.4, out., 2014. 
MASTROIANNI, P. de C. Análise dos aspectos legais das prescrições de medicamentos. Revista de Ciências Farmacêuticas Básica e Aplicada, v. 30, n. 2, p. 173-176, 2009.

NASCIMENTO, P. S.; MAGALHÃES, I. R. S. Análise da prescrição de antimicrobianos dispensados em uma rede de drogarias da região Norte do Brasil. Rev. Bras. Farm. 94 (3): $211-218.2013$.

NICOLINI, P.; NASCIMENTO, J. W. L.; GRECO, K. V.; MENEZES, F. G. Fatores relacionados à prescrição médica de antibióticos em farmácia pública da região Oeste da cidade de São Paulo, 2008. Ciência \& Saúde Coletiva, 13(Sup):689-696, 2008.

OLIVEIRA, A. O. T.et al. Atenção farmacêutica na antibioticoterapia. Visão Acadêmica, Curitiba, v. 5, n. 1, p. 7-14, Jan/Jun, 2004.

OLIVEIRA, K. R.; DESTEFANI, S. R. A. Perfil da prescrição e dispensação de antibióticos para crianças em uma Unidade Básica de Saúde (UBS) no município de ljuí - RS. Revista de Ciências Farmacêuticas Básica e Aplicada. v.32, n.3, p. 395-401, 2011.

ORGANIZAÇÃO MUNDIAL DE SÁUDE. Uso racional de medicamentos. Fact sheet $\mathrm{n}^{\circ}$ 338. Maio, 2010.

PEGORARO, F.; GONÇALVES, N. M. F. M. Análise de erros no contexto das prescrições médicas de antimicrobianos em uma farmácia privada da cidade de Quedas do Iguaçu. Revista UNIANDRADE; 17(2): 51-62. 2012.

PESCADOR, L; SPADA, P. K. W. D. S. Perfil da venda de antibióticos em uma rede de farmácias do Rio grande do Sul no período de outubro de 2014 a março de 2015. III Congresso de Pesquisa e Extensão da FSG. Caxias do Sul - RS, de 15 a 17 de Set 2015. ISSN 2318-8014. 2015.

SANAJOTTO, B. S, PILOTO, J. A. R. Análise da prescrição de antimicrobianos dispensados em uma farmácia do Paraná, Maringá. Braz J. Surg Clin Res. 2014 Setnov;8(3):15-19. 2014. 
RANG, H. P.; DALE, M. M.; RITTER, J. M.; FlOWER, R. J.; HENDERSON, G. Farmacologia. 7 ed. Rio de Janeiro: Elsevier, 2011.

SANTOS, V.; NITRINI, S.M.O.O. Indicadores do uso de Medicamentos Prescritos e de Assistência ao Paciente de Serviços de Saúde. Revista Saúde Pública, v.38, n.6, p.81926, 2004.

SECOLLI, S. R. Interações medicamentosas: fundamentos para a prática clínica de Enfermagem. Revista da Escola de Enfermagem da USP, v. 35, n. 1, 2001.

SILVA, E. R. B.; BANDEIRA, V. A. C.; OLIVEIRA, K. R. Avaliação das prescrições dispensadas em uma farmácia comunitária no município de São Luiz Gonzaga-RS. Revista de Ciências Farmacêuticas Básica e Aplicada, v. 33, n. 2, p. 275-281, 2012.

SILVÉRIO, M. S.; LEITE, I. C. G. Qualidade das prescrições em município de Minas Gerais: uma abordagem farmacoepidemiológica. Revista da Associação Médica Brasileira, São Paulo, v. 56, n. 6, p. 675-680, set. 2010.

VIEIRA, F. A formação de aviadores no Brasil e no Mundo: O status quo e a necessidade de mudança no paradigma vigente. Revista Conexão SIPAER, v. 1, n. 3, jul. 2010.

VIEIRA, F. S. Assistência farmacêutica no sistema público de saúde no Brasil. Rev Panam Salud Pública. 2010; 27:149-56. 2010.

VIEIRA, P. N.; VIEIRA, S. L. V. Uso irracional e resistência a antimicrobianos em hospitais. Arq. Cienc. Saúde UNIPAR, Umuarama, v. 21, n. 3, p, 209-212, 2019.

WANNMACHER, L. Uso indiscriminado de antibióticos e resistência microbiana: uma guerra perdida? Uso racional de medicamentos: temas selecionados, Brasília, v. 1, n. 4, mar. 2006. 